$\mathbf{T}$ here is a danger with digital humanities instruction of falling into the trap of buttonology. By buttonology, we do not mean the study of buttons, nor do we intend the derision of August Strindberg, who, in his story "The Isle of the Blessed," coined the word buttonology to mock scholarly pedantry.

Buttonology is, in its simplest terms, software training that surveys different features of an interface in an introductory manner. In a library one-shot, teaching the library discovery system or showing how to perform an advanced search in a database would be buttonology. Knowing how to upload texts into a tool like Voyant does not help researchers think about what texts should be uploaded, how selecting data relates to a research question, or even what constitutes an effective research question. This type of teaching does not encourage critical thinking, yet digital humanities instruction, in our experience, is frequently focused on showing how to use software rather than reflect on the broader context.

There is a growing body of literature on digital humanities instruction in libraries that extends back at least to $2013 .{ }^{1}$ Until recently, this literature mostly sidestepped information literacy, focusing on the nature of librarian-faculty classroom collaborations or on teaching digital humanities tools. However, works by Andrea Baer and Krista White have begun to trace connections to ACRL's "Framework for Information Literacy for
Higher Education," opening a line of inquiry that helps connect digital humanities work to the instructional mission of our profession and encourages librarians to reconceptualize their approach to teaching by incorporating digital pedagogy. ${ }^{2}$

\section{Digital pedagogy}

Digital pedagogy is quickly becoming commonplace among faculty and across disciplines and is often referred to as critical pedagogical perspective. Stewart Varner defines digital pedagogy as the act of "creatively and critically incorporat[ing] technology into assignments in ways that truly enhance student engagement and encourage them to confront how technology impacts the work they do." ${ }^{3}$

For all of the literature on digital humanities and libraries, librarians have only just begun exploring their teaching role in the digital humanities. Since this teaching role is often tutorial-based, the literature is mostly practical with a focus on how best to present digital tools. However, there are a few

John E. Russell is digital humanities librarian and associate director for the Center for Humanities and Information at Pennsylvania State University, email: jer308@psu.edu, and Merinda Kaye Hensley is associate professor and digital scholarship liaison and instruction librarian at the University of Illinois at UrbanaChampaign, email: mhensle1@illinois.edu

c 2017 John E. Russell and Merinda Kaye Hensley 
examples where librarians are expressing increased dissatisfaction with the limited scope of technology instruction.

In a recent Council on Library Resources (CLIR) paper, Paige Morgan expressed "some frustration with the workshop approach, specifically how it feeds into researchers' desires to learn new tools quickly at the expense of a more thoughtful engagement with the broader methods and questions of digital humanities, including the type of questions digital humanities allows researchers to ask." ${ }^{4}$

In last year's $d b+l i b$ special issue, Sarah Stanley and Micah Vandegrift described the tool-focused state of digital humanities instruction (both inside and outside of the library), with Stanley specifically arguing that "we should be teaching students resources for working better (both together and alone), rather than what the GUI on different mapping tools looks like." 5 The desire for a more information-literate approach to digital humanities instruction is also the motivation behind Susan Powell and Ningning Nicole Kong's article advocating for an intensive workshop model that "gives librarians the space to move beyond solely skills-based learning outcomes to more advanced, situated knowledge."

These librarians are expressing a desire to increase their focus on the digital humanities context rather than on software specifics by moving from a skills-based approach to a more conceptual form of teaching. Creating educational experiences with the sole goal of showing how to manipulate software interfaces outside of a larger context is not satisfying to the instructor, and it does not get at the "thoughtful engagement" that Morgan mentions. After all, the most significant barrier to digital humanities practice is not how to make the software function, it is the critical engagement with digital methodologies, as well as humanities sources as data, and then organizing data in a manner that allows for subsequent analysis and presentation.

How can we make our digital humanities instruction more information-literate? What might digital pedagogy look like if teaching a session on text analysis or Palladio promoted the kinds of critical reflection as called for by the Framework? We could not find much in this area in the literature, and a quick search in the still-new ACRL Framework Sandbox reveals very few submissions related to the humanities, without a single entry for "digital humanities."

We propose digital humanities instruction should be thought of as a two-step instructional process-adding value to buttonology with a focus on further developing research questions, managing data, and refining methodology. It isn't that skills-based instruction isn't valuable, we know that it is. However, the theories and concepts presented in the Framework align well with the definition of digital pedagogy, especially around concepts of critical reflective practice. As digital humanities projects find their way into the classroom, we are provided with the opportunity to collaborate with faculty to uncover the intersections between digital humanities methodologies and information literacy concepts. For example, teaching basic mapping literacy and ethical use of data before tool basics will prepare learners with the foundational knowledge needed to create a successful map, now and in the future.

\section{Theories of ACRL Framework: Liminality and metacognition}

How do we encourage critical thinking so scholars can work towards answers to their complex digital scholarship questions (e.g., how selecting data relates to a research question, or even what constitutes an effective research question)? In other words, how do we embrace a critical pedagogical perspective in our digital pedagogy? In addition to the six frames, the Framework outlines several underlying and complementary learning theories-for example, liminal space and metacognition-that can help librarians when designing instruction to go beyond buttonology.

The liminal state is the space where learners have begun to commit to the learning process but are consumed with "digression 
and revisiting." Liminality is not a comfortable place for the learner (nor is it, we would argue, for the teacher), but it is necessary in order to move from being a novice to an expert, as summarized in the language of the Framework. Glynis Cousin reminds us as teachers that it is our responsibility to listen for understanding and to nurture a holding environment for the toleration of confusion. "The idea that learners enter into a liminal state in their attempts to grasp certain concepts in their subjects presents a powerful way of remembering that learning is both affective and cognitive and that it involves identity shifts which can entail troublesome, unsafe journeys." ${ }^{8}$ In other words, we are guiding scholars along the process of learning how to learn.

There are specific strategies we can implement to help learners escape the recursive spiral of the liminal state they experience while managing complex digital projects:

- One of the most challenging aspects of teaching digital tools is forgetting what it is like to be a novice learner. Sometimes being a near-novice oneself helps you better prepare for the basic problems and frustrations learners are facing. But recognizing liminality is a reminder to you as a teacher that the learning process is not smooth, and it requires anticipating common difficulties and regularly checking in with learners to make sure you are not leaving them behind.

- When meeting with learners one-onone, make sure to use your in-depth reference interview skills to engage in methods discussions. When a learner is in the liminal state, they are not always able to "see the forest for the trees." Your directed questions will illuminate the problems they are having and the solutions they had not seen.

- Pay close attention to the digital humanities work and discussions happening on your own campus, as well as across the academic community. Working through the liminal space may require helping learners make connections to others facing similar problems. Also follow online discussions in order to point your learners to a wide variety of group learning opportunities, such as the active digital humanities community on Slack. ${ }^{9}$

- When designing instructional opportunities, such as workshops and hackathons, pay particular attention to outreach strategies that may bring like-minded learners together, as well as diverse voices. For example, invite the scholar whose project was completed last year to add a more experienced voice to the conversation. By encouraging the formation of learning communities on your campus, you are creating safe spaces to help learners navigate the liminal state with others who may be on the other side of struggling with specific digital project issues.

- In designing instructional activities, guide learners through visualization exercises that help to identify "stuck" places. Making graphic representations of one's thoughts (e.g., concept maps) can highlight areas that require clarification.

Metacognition, an educational psychology term, is an essential component of the learning process. As defined by Jennifer Livingston, metacognition is "higher order thinking which involves active control over the cognitive processes engaged in learning. ${ }^{10}$ For example, if you watch a Lynda. com tutorial on learning Python and afterwards ask yourself how what you learned applies to your digital project goals, that is metacognition in action. Being increasingly aware of your learning is a reflective practice that helps you to solve problems and build self-awareness. Dale Vidmar points out the importance of affect in the instructional process, “. . . [affect] addresses the students' motivation, their involvement in the learning process, their experience of self-actualization and discovery, and their feelings in context of the library environment."11 The Framework provides illustrations of metacognition and affect through the example dispositions outlined for each frame.

Here are a few specific examples you can apply to your instructional design process to help learners with metacognition: 
- Model the metacognitive process during instruction (or in one-on-one consultations) to ask and reflect on big picture questions such as: "What questions can you answer with this tool?" "What can you not do with this tool?" Keep in mind some answers may be simple (e.g., this tool can only work with data in this way, so it is excluded automatically). Also, "Did I get the results I expected? What could I have done differently?" Start with inquiry and build conversations based on the learner's answers. "Is it the data that does not work? Or is the research question fundamentally wrong to begin with?"

- Collaborate with faculty to teach together, modelling your practices while demonstrating a specific tool. This could include thinking aloud as you make decisions so learners can self-correct assumptions. Also, be aware of your own expert bias so you can demonstrate how to clear obstacles.

- Ask learners to specifically define what is difficult for them during the process of instruction. Digital humanities tools are complex and are based on complex methodologies and research questions. By constructing opportunities for learners to self-question as they move from one task to another, they learn to self-assess their progress and adjust accordingly.

- There are several instructional design activities that promote metacognition: thinkpair-share, one minute paper ("share a key concept learned" or "what comes next?"), and case studies. ${ }^{12}$

\section{Conclusion}

Digital humanities is all about creating new knowledge and understandings including delving into different ways of thinking in a discipline. In all of the focus on digital humanities projects and on whether or not digital humanities work belongs in libraries, we have lost sight of digital humanities librarianship as a practice of librarianship. There is nothing novel about librarians offering instruction in the classroom or workshop settings, and there is nothing novel about librarians working to connect researchers with the resources they need to conduct research. Furthermore, if information literacy instruction is core to our professional practice, it does not make sense to isolate our digital humanities work from it. In fact, being able to articulate digital humanities work in terms of information literacy makes it easier to convey the value of digital work to our peers and administrators.

\section{Acknowledgments}

This column originated from an ACRL 2017 round table discussion, "Beyond Buttonology: Information Literacy and the Digital Humanities," March 24, 2017.

\section{Notes}

1. Andrea Baer, "Critical Information Literacy in the College Classroom: Exploring Scholarly Knowledge Production through the Digital Humanities," in Information Literacy and Social Justice: Radical Professional Praxis, edited by Lua Gregory and Shana Higgins (Los Angeles: Library Juice Press, 2013): 99-120; John Russell, "Teaching Digital Scholarship in the Library," $d b+l i b$, http:// acrl.ala.org/dh/2013/01/24/teaching-digitalscholarship-in-the-library/ (accessed October 27, 2017), and "Teaching Digital Scholarship in the Library: Course Evaluation," $d b+l i b$, http://acrl.ala.org/dh/2013/07/24/teaching -digital-scholarship-in-the-library-course -evaluation/ (accessed October 27, 2017).

2. Baer, "Critical Information Literacy;" Krista White, "Visualizing Oral Histories: A Lab Model Using Multimedia DH to Incorporate ACRL Framework Standards into Liberal Arts Education," College \& Undergraduate Libraries 24 (2017): 1-25, http://dx.doi.org /10.1080/10691316.2017.1325722.

3. Stewart Varner, "Library Instruction for Digital Humanities Pedagogy in Undergraduate Classes," in Laying the Foundations: Digital Humanities in Academic Libraries, edited by John W. White and Heather Gilbert (West Lafayette, IN: Purdue University Press, 2016): 205-222.

(continues on page 600) 
hired was because of my professional accomplishments, so it was important to continue to invest time in those activities.

What my calendar does not show in those first 100 days is the number of times I went next door to ask my associate dean a question about policies, or how many times I disturbed my human resources and budget professional to get one more clarification about a procedure. Between the two of them, they had more than 50 years of combined experience in the library, and I was so grateful to have all that institutional knowledge readily available. They assured me that I would eventually learn the complex systems of the university, but also reminded me that just because the library had "always" done something a certain way did not mean that I could not change it if it did not continue to make sense.

\section{Conclusion}

Powers, Garnar, and Fife each used their first 100 days to learn about their new team members and institutions. Each of their experiences were different, with Powers being confronted by something new each day and Fife and Garnar entering stable situations, but uprooting their personal lives. Transitions for other new leaders will be unique, but leadership is about persisting humbling, asking questions, and adapting to new environments.

This is part two in a three-part series. In part three, the authors will look back at their first year. They will explore what worked and what did not, and what lessons they learned as new deans and directors. $\neq 2$

("Beyond buttonology," continues from page 591)

4. Hannah Rasmussen, Brian Croxall, and Jessica Otis, "Exploring How and Why Digital Humanities Is Taught in Libraries," in $A$ Splendid Torch: Learning and Teaching in Today's Academic Libraries, edited by Jodi Reeves Eyre, John C. Maclachlan, and Christa Williford (Washington, D.C.: Council on Library and Information Resources, September 2017): 69-88, https://www.clir.org/pubs /reports/pub174/humanities.pdf (accessed October 27, 2017).

5. Sarah Stanley and Micah Vandegrift, "Cross-disciplinarity at the Crossroads," in Digital Humanities in the Library/Of the Library: $A d b+$ lib Special Issue, edited by Caitlin Christian-Lamb, et al., http://acrl.ala. org/dh/2016/07/29/cross-disciplinarity-atthe-crossroads/ (accessed October 27, 2017).

6. Susan Powell and Ningning Nicole Kong, "Beyond the One-shot: Intensive Workshops as a Platform for Engaging the Library in Digital Humanities," College \& Undergraduate Libraries 24 (2017): 1-16, http://dx.doi.org/10.1080/10691316.2017.13 36955 (accessed October 27, 2017).

7. Jan H. F. Meyer and Ray Land, eds., Overcoming Barriers to Student Understanding: Threshold Concepts and Troublesome
Knowledge (London and New York: Routledge, 2006).

8. Glynis Cousin, "Threshold Concepts, Troublesome Knowledge and Emotional Capital: An Exploration into Learning about Others," in Meyer and Land, eds., Overcoming Barriers, 139.

9. See the Slack Community on digital humanities: https://digitalhumanities. slack.com, HASTAC (Humanities, Arts, Science, and Technology Alliance and Collaboratory): https://www.hastac.org/abouthastac, or Digital Humanities Now: http:// digitalhumanitiesnow.org.

10. Jennifer A. Livingston, "Metacognition: An Overview," State University of New York at Buffalo, Graduate School of Education, 1997, http://gse.buffalo.edu/fas/shuell/cep564 /metacog.htm (accessed October 27, 2017).

11. Dale J. Vidmar, "Affective Change: Integrating Pre-Sessions in the Students' Classroom Prior to Library Instruction," Reference Services Review 26, no. 3/4 (1998): 80.

12. For strategies on how to design instruction for technical tools, see Data Carpentry at www.datacarpentry.org and Data Carpentry Instructor Training at http://carpentries.github. io/instructor-training/. $\neq 2$ 